\title{
NUMERICAL HEAT TRANSFER ANALYSIS OF WASTE HEAT EXCHANGER FOR EXHAUST GAS ENERGY RECOVERY
}

\author{
M.R.M. Nawi", A.M.I. Mamat and H. Ismail \\ Faculty of Mechanical Engineering, Universiti Teknologi MARA \\ 40450 Shah Alam, Selangor, Malaysia \\ *Email: muhad.rozi@gmail.com \\ Phone: +60355435141
}

\begin{abstract}
Waste heat is heat that is usually thrown into the environment even though it could still be reused for some useful and economic purpose. For example, any exhaust gas stream with a temperature of above $80^{\circ} \mathrm{C}$ has the potential for significant waste heat recovery. Therefore, an attempt to reuse the exhaust waste energy to transfer the energy to any energy cycle is a worthwhile effort. In the present study, the waste energy from the exhaust gas of an internal combustion engine is recovered by converting it to ammonia $\left(\mathrm{NH}_{3}\right)$ as an organic operating fluid in the Organic Rankine Cycle (ORC), which aims to produce $3 \mathrm{~kW}$ turbine power. To achieve a specific amount of energy, a key component in waste heat recovery is the heat exchanger. In the present study, a steady-state numerical analysis of heat transfer is conducted for various dimensional configurations of the waste heat exchanger using ammonia. The findings showed that the exhaust gas mass flow rate only has a very minimal effect on the length of the pipe when the exhaust temperature exceeds $400^{\circ} \mathrm{C}$.
\end{abstract}

Keywords: Waste heat recovery; organic Rankine cycle; sustainable energy; waste heat exchanger modeling.

\section{INTRODUCTION}

Waste heat from engines and industrial processes represent an energy resource that is currently not well utilized. Temperatures from as low as $80^{\circ} \mathrm{C}$ to as high as $300^{\circ} \mathrm{C}$ from the processes including exhaust gases from power plants and combustion processes, geothermal energy, solar heat, biomass, etc. can be recovered by generating power using the Organic Rankine Cycle (ORC) [1-4]. This effort becomes an important sustainable method of solving the global energy crisis. The ORC technology is economical, reliable, and scalable, which uses organic operating fluid that has lower boiling temperature than water, for example, R245fa [5]. Other advantages of the ORC are high thermal efficiency, simple turbine, dry expanding process, and no emission of exhaust gases [6, 7]. Fu et al. [8] developed a 250-kW ORC system using R245fa as an operating fluid. The ORC system consists of a pump, preheater, evaporator, turbine, generator, condenser, as well as hot and cool water circulation systems. From the testing conducted, the results demonstrated that the present system responded very rapidly with a change in the heat source temperature. In addition, their study also demonstrated that the system's thermal efficiency and net power output increased linearly with an increase in the temperature of the heat source. 
Fluid selection plays an important role in the ORC system design. Operating fluids are classified into three types: dry, isentropic, and wet [9, 10]. Organic fluids are always isentropic or dry; these fluids have better thermal properties in waste heat recovery systems than wet fluids like water [6]. In the past, researchers have used refrigerants including HFE7000 [11], HFE7100 [12], R227ea [13], R245fa [6, 14], and $\mathrm{R} 134 \mathrm{a}$ [15] with the ORC thermal efficiency ranging from $3.8 \%$ to $12.9 \%$. Most of the working fluids are expensive and also have certain environmental drawbacks. Synthetic fluids such as silicone oil, R245fa, and R134a suffer from these disadvantages [16]. Further, ORC systems often require large filling amounts as the heat exchangers need to be large. Therefore, several ORC suppliers are investigating the use of naturally occurring substances such as hydrocarbons, $\mathrm{NH}_{3}$, and $\mathrm{CO}_{2}$ [16]. In published literature, ORC researches have largely focused on the operating fluid performance analysis [6, 11-15, 17-21]; there is a lack of research on the geometric specifications of heat exchangers and heat transfer analysis (only a few studies exist such as Jung and Krumdieck [22] and Hossain and Bari [23]). Since a waste heat exchanger (WHE) is one of the key components in waste heat recovery, the present study performs heat transfer analysis of a simple counterflow WHE that could provide significant information for the development of $3 \mathrm{~kW}-\mathrm{ORC}$ waste heat recovery system from the exhaust gas of ICE using ammonia as an organic operating fluid. Since the ORC-NH efficiency is estimated to be $25 \%$ [24], the exhaust gas from ICE needs to produce heat transfer rates of $12 \mathrm{~kW}$ through counterflow type of WHE.

\section{METHODOLOGY AND MATERIAL}

\section{Organic Rankine Cycle}

The organic Rankine cycle (ORC) layout is depicted in Figure 1. The heat source of the ORC is the engine exhaust of an internal combustion engine (ICE). The ICE exhaust gas temperature is between $200^{\circ} \mathrm{C}$ and $900^{\circ} \mathrm{C}$, depending on engine load. Ammonia $\left(\mathrm{NH}_{3}\right)$ is chosen as the organic operating fluid (OOF) in the ORC due to high effectiveness, with a maximum value of 0.25 , compared to hydrocarbons like propane $\left(\mathrm{C}_{3} \mathrm{H}_{8}\right)$ in which the maximum value of effectiveness is $\varepsilon=0.16$ [24]. In Figure 1, the exhaust gas as a heat source is shown to enter the WHE and the heat is transferred into the OOF. The phase of the OOF will change from liquid to superheated when a sufficient amount of heat is transferred. Then, the mechanical energy is obtained when the superheated OOF expands in the turbine. The cycle efficiency of the ORC is assumed to be $25 \%$.

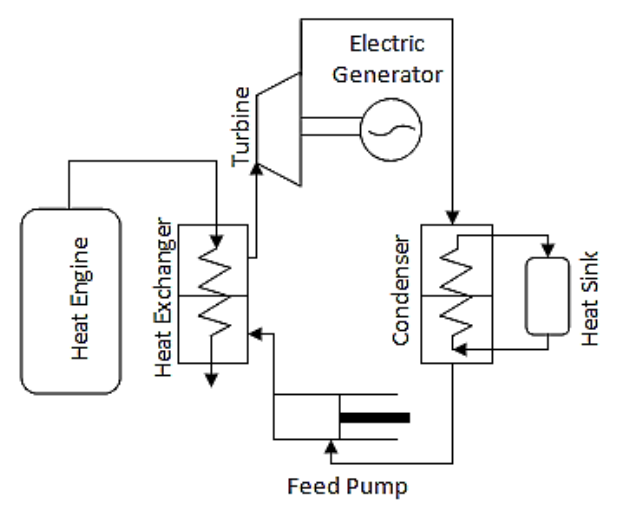

Figure 1. ORC layout. 


\section{Waste Heat Exchanger Modeling}

The waste heat exchanger (WHE) is modeled as a simple double pipe counterflow heat exchanger that consists of two concentric tubes, as shown in

Figure 2. The exhaust gas flows in a 1 inch $(25.4 \mathrm{~mm})$ diameter tube, and the $\mathrm{OOF}$ through the annular space with the inner diameter of the annular is $45.4 \mathrm{~mm}$. The thickness of the exhaust tube is set based on the standard 1-inch $(25.4 \mathrm{~mm})$ diameter pipe, that is, $1.24 \mathrm{~mm}, 1.65 \mathrm{~mm}, 2.11 \mathrm{~mm}$, and $2.77 \mathrm{~mm}$. The inlet exhaust temperatures tested are in the range of $200^{\circ} \mathrm{C}-900^{\circ} \mathrm{C}$. The inlet $\mathrm{OOF}$ temperature is set at $40^{\circ} \mathrm{C}$. The analysis is simplified as a single-phase flow with temperature dependent on specific heat.

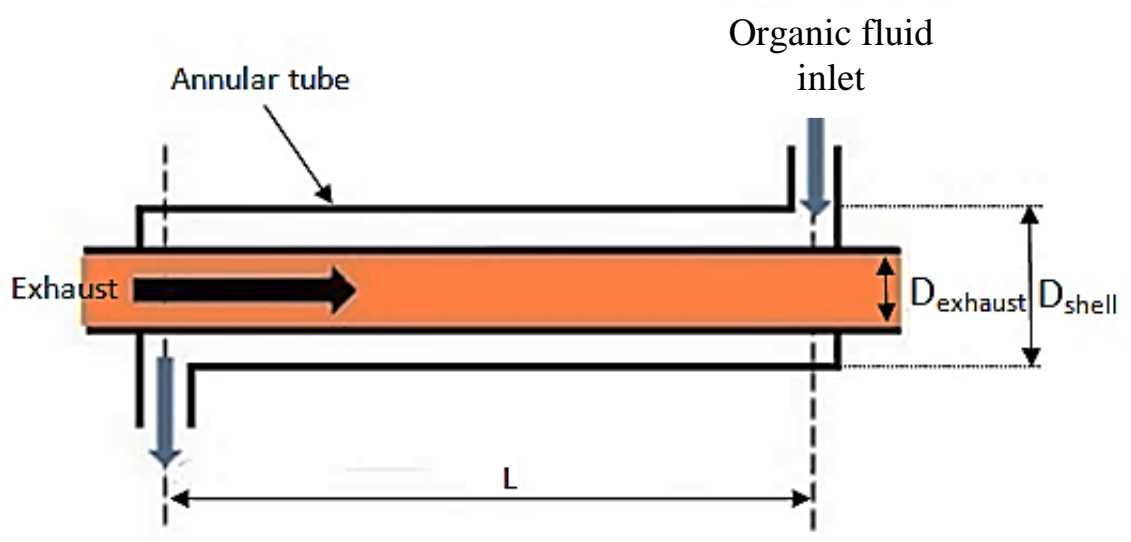

Figure 2. Schematic layout of counterflow WHE.

The method used in the heat exchanger analysis is log mean temperature difference (LMTD). Since heat exchangers usually operate for long periods of time with no change in their operating conditions, the WHE was modeled as a steady-flow device. In the LMTD method, the heat transfer rate $\dot{Q}$ is given as

$$
\dot{\mathrm{Q}}=\mathrm{UA}_{\mathrm{s}} \Delta \mathrm{T}_{\mathrm{lm}} \text {, }
$$

where $U$ is the overall heat transfer coefficient, $A_{s}$ is the heat transfer area, and $\Delta T_{l m}$ is an appropriate average temperature difference between the exhaust gas and OOF. The overall heat transfer coefficient, $\mathrm{U}$, is a combination of all thermal resistance between the exhaust gas and OOF flow and is given by

$$
\frac{1}{\mathrm{U}}=\frac{1}{\mathrm{~h}_{\text {conv,exh }}}+\frac{\ln \left(\mathrm{D}_{\mathrm{o}} / \mathrm{D}_{\mathrm{i}}\right)}{2 \pi \mathrm{k}_{\text {pipe }} \mathrm{L}}+\frac{1}{\mathrm{~h}_{\text {conv }, \mathrm{OOF}}} .
$$

$\Delta \mathrm{T}_{\mathrm{Im}}$ is defined as

$$
\Delta \mathrm{T}_{\mathrm{lm}}=\frac{\Delta \mathrm{T}_{1}-\Delta \mathrm{T}_{2}}{\ln \left(\Delta \mathrm{T}_{1} / \Delta \mathrm{T}_{2}\right)}
$$


where $\Delta \mathrm{T}_{1}$ and $\Delta \mathrm{T}_{2}$ represent the temperature difference between the exhaust gas and OOF at the two ends (inlet and outlet) of the WHE (

Figure 2) with the counterflow heat exchanger type:

$$
\begin{aligned}
& \Delta \mathrm{T}_{1}=\mathrm{T}_{\mathrm{h}, \text { in }}-\mathrm{T}_{\mathrm{c}, \text { out }} \\
& \Delta \mathrm{T}_{2}=\mathrm{T}_{\mathrm{h}, \text { out }}-\mathrm{T}_{c, \text { in }} .
\end{aligned}
$$

The resistance network for the exhaust pipe that separates the exhaust flow and OOF is illustrated in

Figure 3.

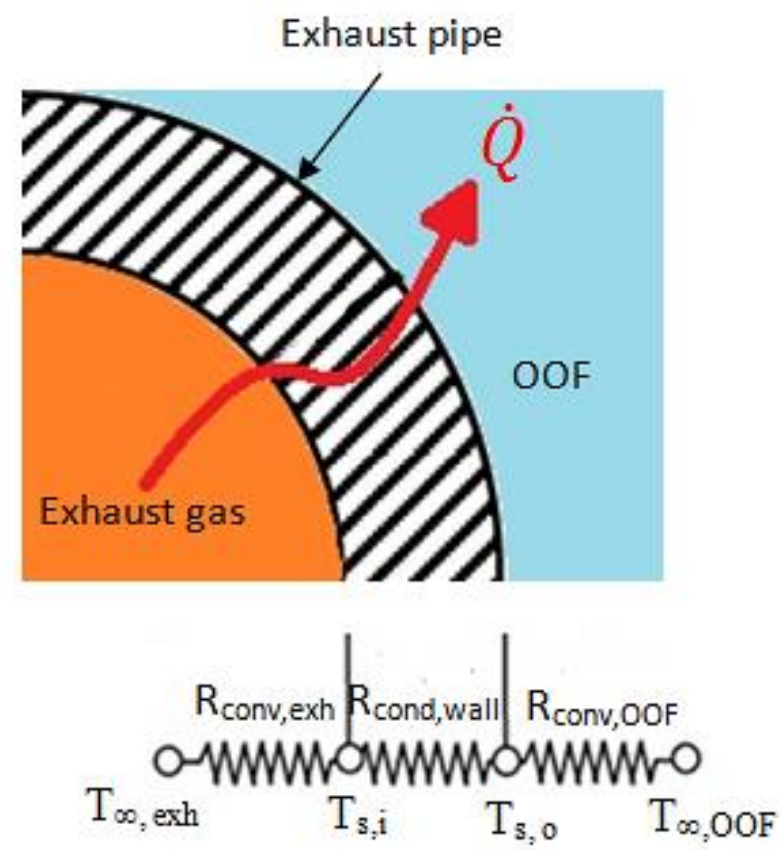

Figure 3. Schematic representation of a cross-section of the exhaust pipe with thermal resistance network.

The exhaust is considered to have a fully developed turbulence flow $\left(3 \times 10^{3} \leq\right.$ $\operatorname{Re} \leq 5 \times 10^{6}$ ) with the ratio of convective to conductive heat transfer across that is, the Nusselt number $(\mathrm{Nu})$ is calculated using the Gnielinski correlation [25] in the following manner:

$$
\mathrm{Nu}=\frac{(\mathrm{f} / 8)(\mathrm{Re}-1000) \mathrm{Pr}}{1+12.7(\mathrm{f} / 8)^{1 / 2\left(\mathrm{Pr}^{2} / 3-1\right)}}
$$

where $\mathrm{f}$ is the pipe friction factor that is estimated using Colebrook's equation in the following manner:

$$
\frac{1}{\sqrt{\mathrm{f}}} \approx-1.8 \log \left[\frac{6.9}{\mathrm{Re}}+\left(\frac{\varepsilon / \mathrm{D}}{3.7}\right)^{1.11}\right]
$$


where $\varepsilon$ is the pipe surface roughness and $\mathrm{D}$ is the diameter of the pipe.

\section{RESULTS AND DISCUSSION}

As mentioned earlier, the present study deals with steady state heat transfer analysis of WHE that could provide significant information for the development of a $3 \mathrm{~kW}$-ORC waste heat recovery system from the exhaust gas of ICE using ammonia as an operating fluid. Since the efficiency of $\mathrm{ORC}-\mathrm{NH}_{3}$ is estimated to be $25 \%$ [24], the exhaust gas from ICE is needed to produce heat transfer rates of $12 \mathrm{~kW}$ through counterflow WHE. During analysis, parameters such as different exhaust gas temperature, mass flow rate, defined temperature of operating fluid, and WHE geometry configurations were taken into account and presented here.

Figure 4 depicts the relationship between the Nusselt number and the required length of pipe (thickness $1.65 \mathrm{~mm}$ ) for different temperatures and mass flow rates of inlet exhaust gas from ICE. The Nusselt number shows an exponential decreasing trend with the inlet exhaust gas temperatures $T_{h, i n}$, thereby indicating that the conduction heat transfer becomes more effective with an increase in exhaust gas temperature, that is, higher temperature difference in WHE. This phenomenon complies with the classical theories of heat transfer [26] and could be explained as follows: with the large amount of heat need to be transferred to the operating fluid, thus requires the heat transfer mode which has better rate of heat transfer i.e. conduction. Therefore, as the exhaust gas temperature increased, the surface area of heat transfer decreased due to reduced domination of convection (convection $\propto$ surface area, $A_{s}$ ), as indicated in Figure 5. This is in line with the results of pipe length, in which the pipe length also decreases exponentially with the exhaust gas temperature. In Figure 4, as the pipe diameter is fixed, the length of pipe rapidly decreases for exhaust gas temperatures ranging from $200^{\circ} \mathrm{C}$ to $300^{\circ} \mathrm{C}$ and beyond $300^{\circ} \mathrm{C}$. Thus, it can be said that the system responds very rapidly as the heat source temperature changes, as discovered by Fu et al. [8]. 


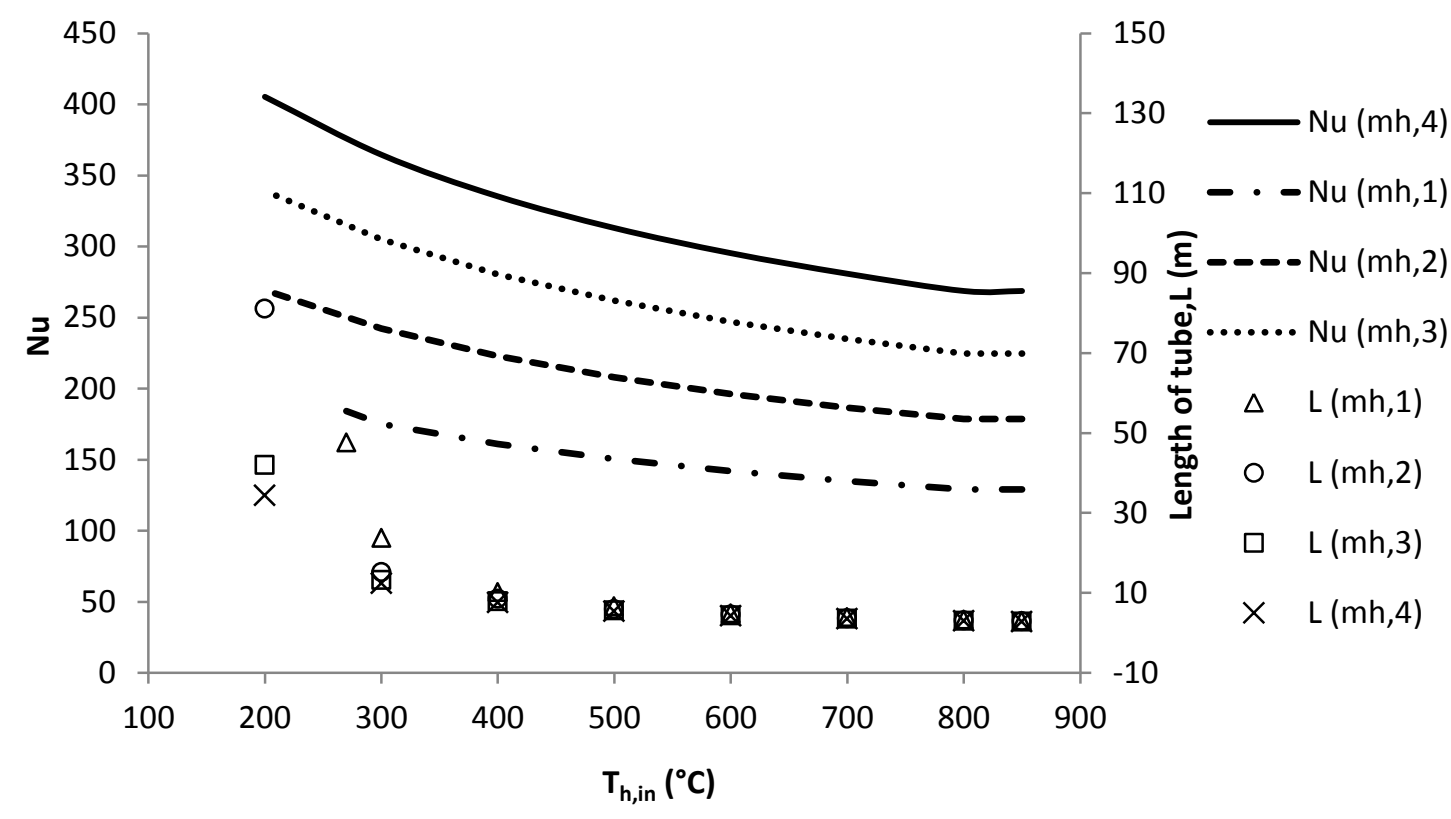

Figure 4. Nusselt number, $\mathrm{Nu}$, and length of tube, $\mathrm{L}$ (pipe thickness $=1.65 \mathrm{~mm}$ ) required for the defined inlet exhaust temperatures and exhaust gas mass flow rates $\left(\boldsymbol{m}_{\boldsymbol{h}, \mathbf{1}}=0.05\right.$

$$
\left.\mathrm{kg} / \mathrm{s} ; \boldsymbol{m}_{\boldsymbol{h}, \mathbf{2}}=0.075 \mathrm{~kg} / \mathrm{s} ; \boldsymbol{m}_{\boldsymbol{h}, \mathbf{3}}=0.1 \mathrm{~kg} / \mathrm{s} ; \boldsymbol{m}_{\boldsymbol{h}, \mathbf{4}}=0.125 \mathrm{~kg} / \mathrm{s}\right)
$$

With regard to the mass flow rate of exhaust gas, the trend shows that the Nusselt number has smaller values for a lower mass flow rate (Figure 4). It is also observed that the exhaust gas mass flow rate shows a very minimal effect on the length of the pipe at inlet exhaust temperatures of above $400^{\circ} \mathrm{C}$. Again, the classical theories of heat transfer could explain these results. The level of mass flow rate corresponds to the level of the heat source. Therefore, as the heat source increases, the conduction heat transfer becomes more dominant, the Nusselt number becomes smaller, and surface area is less significant. Moreover, the heat transfer surface area shows a very small effect on the defined OOF temperatures $T_{c \text {,out }}$ when the exhaust temperatures are above $400^{\circ} \mathrm{C}$, thereby indicating that the conductive heat transfer becomes more dominant (Figure 5). 


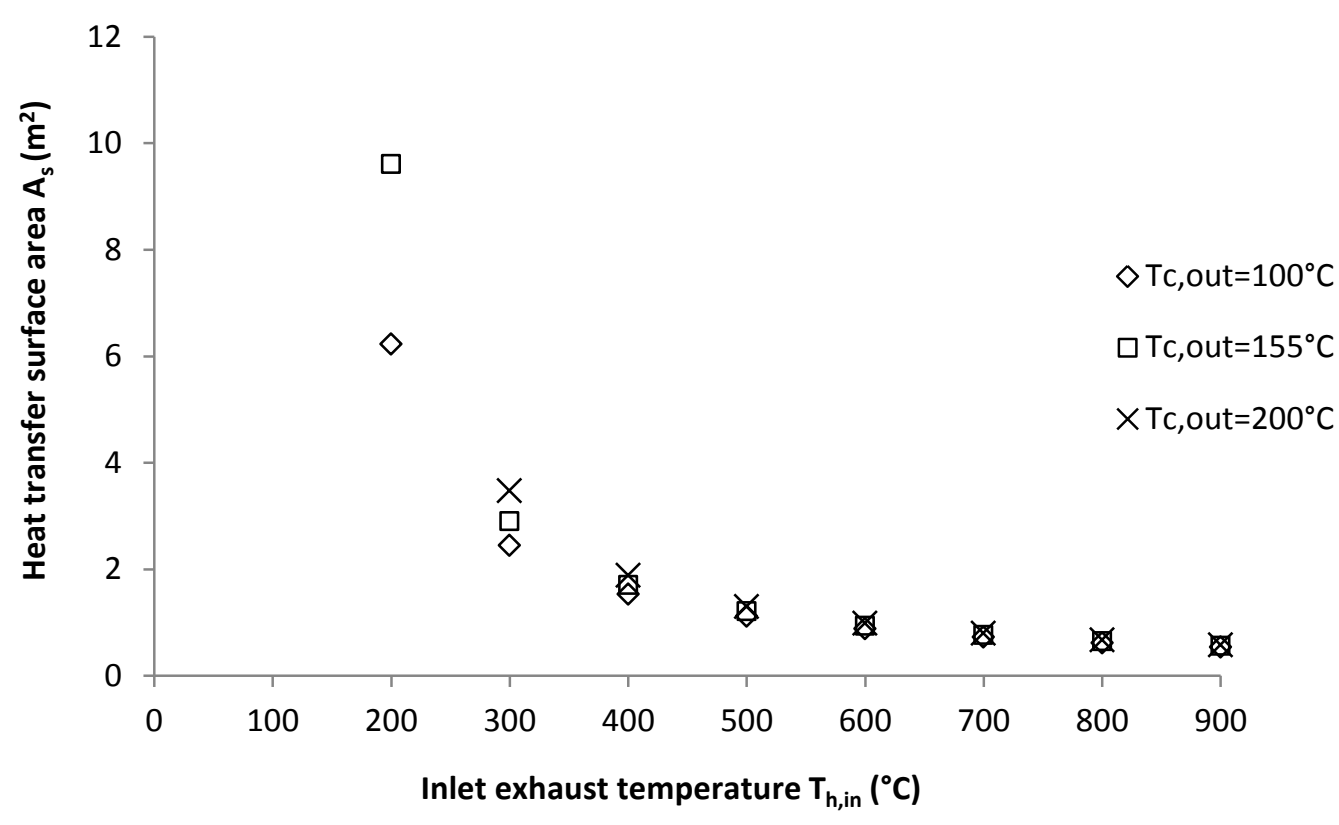

Figure 5. Heat transfer surface area required for different inlet exhaust temperatures with defined outlet OOF temperatures

Figure 6 depicts the OOF mass flow rate $m_{c}$ and the pipe length with various thicknesses- $1.24 \mathrm{~mm}, 1.65 \mathrm{~mm}, 2.11 \mathrm{~mm}$, and $2.77 \mathrm{~mm}$ for the defined outlet temperature of OOF $T_{c, \text { out }}$. In the figure, the inverse relation between the outlet OOF temperature and the OOF mass flow rate is illustrated, thereby implying that to heat up the outlet OOF to a higher temperature, a lesser amount of OOF is required (lower mass flow rate). This is understandable, as to heat a substance to a higher temperature using a specific heat source, the amount of the substance must be reduced. Figure 6 also depicts that the outlet temperature of OOF has a very minimal effect on the length of the pipe for a specific pipe thickness. The figure also shows that when a thicker pipe is used in WHE, a longer pipe is required. This is understandable as thicker pipe reduces the conduction heat transfer rates and, thus, it compensates with convection heat transfer. The effect of the WHE pipe thickness to the overall heat transfer coefficient $U$ is presented in Figure 7. The figure shows that the increase in pipe thickness from 1.24 $\mathrm{mm}$ to $2.77 \mathrm{~mm}$ causes a reduction in the overall heat transfer coefficient by $55 \%$. Theoretically, the overall heat transfer coefficient refers to how well heat is conducted through the medium (across the pipe). It indicates that during conduction heat transfer, small changes in pipe thickness have a significant impact on the overall heat transfer coefficient. 


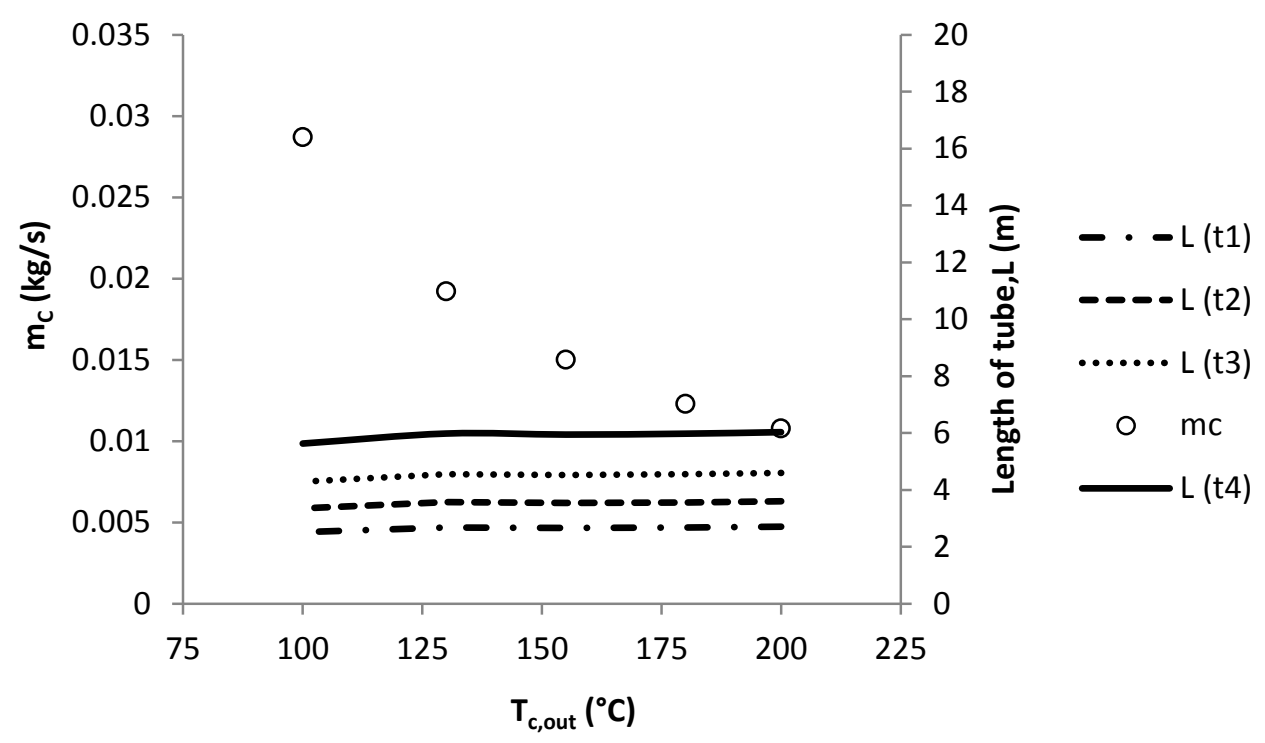

Figure 6. OOF mass flow rate and length of tube required for various thicknesses $\mathrm{t}\left(\mathbf{t}_{\mathbf{1}}=\right.$ $\left.1.24 \mathrm{~mm} ; \mathbf{t}_{\mathbf{2}}=1.65 \mathrm{~mm} ; \mathbf{t}_{\mathbf{3}}=2.11 \mathrm{~mm} ; \mathbf{t}_{\mathbf{4}}=2.77 \mathrm{~mm}\right)$ at the defined outlet temperature of OOF.

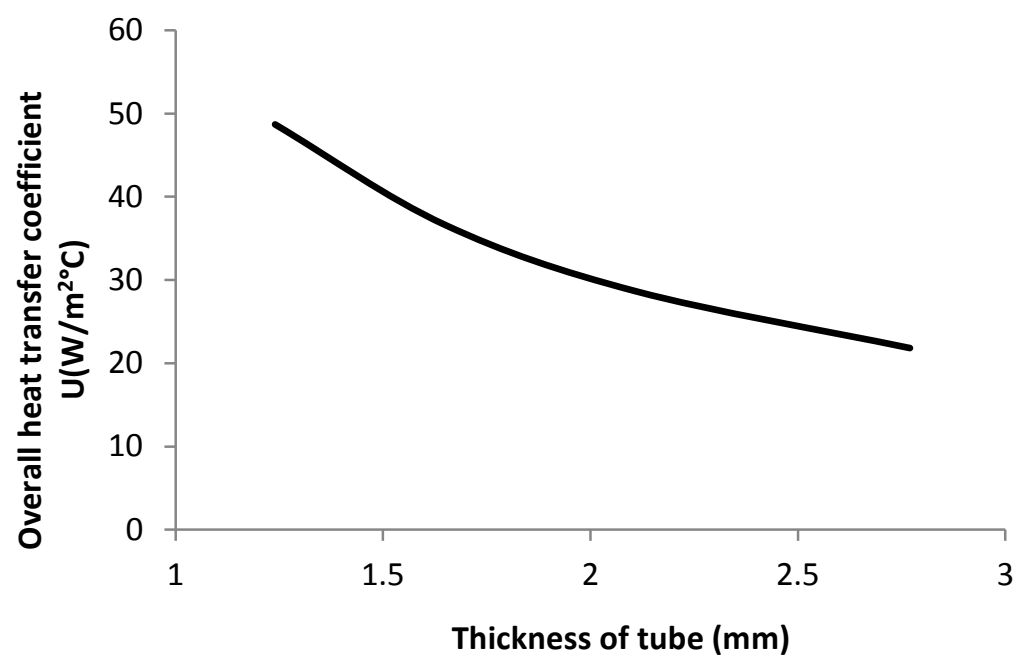

Figure 7. Effects of WHE pipe thickness on the overall heat transfer coefficient, U.

\section{CONCLUSIONS}

In this study, a numerical steady-state heat transfer analysis of WHE for the development of a $3 \mathrm{~kW}$-ORC waste heat recovery system from the exhaust gas of ICE using ammonia as an organic working fluid was conducted. The analysis revealed that conduction heat transfer is more effective when the exhaust gas temperatures are above $400^{\circ} \mathrm{C}$. At exhaust gas temperatures of above $400^{\circ} \mathrm{C}$, the exhaust gas mass flow rate has a minimal effect on the pipe length. Furthermore, the outlet OOF temperatures show very little effect on the length of pipe for a specific pipe thickness. Lastly, increasing pipe thickness from $1.24 \mathrm{~mm}$ to $2.77 \mathrm{~mm}$ reduced the overall heat transfer coefficient by $55 \%$. 


\section{ACKNOWLEDGEMENTS}

The authors would like to thank the Universiti Teknologi MARA, Malaysia (UiTM) for their funding and support of the project under the grant no. 600-RMI/ERGS 5/3 (32/2013).

\section{REFERENCES}

[1] Wei D, Lu X, Lu Z, Gu J. Performance analysis and optimization of organic Rankine cycle (ORC) for waste heat recovery. Energy Convers Manage. 2007;48:1113-9.

[2] Borsukiewiczgozdur A, Nowak W. Comparative analysis of natural and synthetic refrigerants in application to low temperature Clausius-Rankine cycle. Energy2007. p. 344-52.

[3] Drescher U, Bruggemann D. Fluid selection for the organic Rankine cycle (ORC) in biomass power and heat plants. Applied Thermal Engineering. 2007;27:223-8.

[4] Nowak W, Borsukiewicz-Gozdur A, Stachel AA. Using the low-temperature Clausius-Rankine cycle to cool technical equipment. Applied Energy. 2008;85:582-8.

[5] Zyhowski GJ, Brown AP, Achaichia A. HFC-245fa working fluid in organic Rankine cycle - A safe and economic way to generate electricity from waste heat. The 23rd International Conference on Efficiency, Cost, Optimization, Simulation and Environmental Impact of Energy. Lausanne, Switzerland; 2010.

[6] Hung TC, Shai TY, Wang SK. A review of organic rankine cycles (ORCs) for the recovery of low-grade waste heat. Energy. 1997;22:661-7.

[7] Hung TC. Waste heat recovery of organic Rankine cycle using dry fluids. Energy Conversion and Management2001. p. 539-53.

[8] Fu BR, Lee YR, Hsieh JC. Design, construction, and preliminary results of a 250-kW organic Rankine cycle system. Applied Thermal Engineering. 2015;80:339-45.

[9] Borsukiewiczgozdur A, Nowak W. Maximising the working fluid flow as a way of increasing power output of geothermal power plant. Applied Thermal Engineering. 2007;27:2074-8.

[10] Liu BT, Chien KH, Wang CC. Effect of working fluids on organic Rankine cycle for waste heat recovery. Energy. 2004;29:1207-17.

[11] Qiu G, Shao Y, Li J, Liu H, Riffat SB. Experimental investigation of a biomassfired ORC-based micro-CHP for domestic applications. Fuel. 2012;96:374-82.

[12] Jradi M, Riffat S. Experimental investigation of a biomass-fuelled micro-scale tri-generation system with an organic Rankine cycle and liquid desiccant cooling unit. Energy. 2014;71:80-93.

[13] Klonowicz P, Borsukiewicz-Gozdur A, Hanausek P, Kryłłowicz W, Brüggemann D. Design and performance measurements of an organic vapour turbine. Applied Thermal Engineering. 2014;63:297-303.

[14] Chang JC, Chang C-W, Hung TC, Lin JR, Huang KC. Experimental study and CFD approach for scroll type expander used in low-temperature organic Rankine cycle. Applied Thermal Engineering. 2014;73:1444-52. 
[15] Twomey B, Jacobs PA, Gurgenci H. Dynamic performance estimation of smallscale solar cogeneration with an organic Rankine cycle using a scroll expander. Applied Thermal Engineering. 2013;51:1307-16.

[16] Ohman $\mathrm{H}$. Implementation and evaluation of a low temperature waste heat recovery power cycle using $\mathrm{NH} 3$ in an organic Rankine cycle. Energy. 2012;48:227-32.

[17] Tahseen TA, Ishak M, Rahman MM. Analysis of laminar forced convection of air for crossflow over two staggered flat tubes. International Journal of Automotive and Mechanical Engineering. 2012;6:755-67.

[18] Sahin B, Manay E, Ozceyhan V. Overall heat transfer enhancement of triangular obstacles. International Journal of Automotive and Mechanical Engineering. 2013;8:1278-91.

[19] Tahseen TA, Rahman MM, Ishak M. Heat transfer and pressure drop prediction in an in-line flat tube bundle by radial basis function network. International Journal of Automotive and Mechanical Engineering. 2014;10:2003-15.

[20] Tahseen TA, Ishak M, Rahman MM. A numerical study of forced convection heat transfer over a series of flat tubes between parallel plates. Journal of Mechanical Engineering and Sciences. 2012;3:271-80.

[21] Tahseen TA, Ishak M, Rahman MM. Laminar forced convection heat transfer over staggered circular tube banks: A CFD approach. Journal of Mechanical Engineering and Sciences. 2013;4:418-30.

[22] Jung HC, Krumdieck S. Modelling of organic Rankine cycle system and heat exchanger components. International Journal of Sustainable Energy. 2013;33:704-21.

[23] Hossain SN, Bari S. Waste heat recovery from the exhaust of a diesel generator using shell and tube heat exchanger. ASME 2013 International Mechanical Engineering Congress and Exposition, IMECE 2013. San Diego, CA: American Society of Mechanical Engineers; 2013.

[24] Mamat AMI, Wan Mohamed WAN. Thermal analysis of heat recovery unit to recover exhaust energy for using in organic rankine cycle. Applied Mechanics and Materials. 2013;393:781-6.

[25] Gnielinski G. New equations for heat and mass transfer in turbulent pipe and channel flow. International Chemical Engineering. 1976;16:359-68.

[26] Incropera FP, DeWitt DP, Bergman TL, Lavine AS. Fundamentals of heat and mass transfer. Sixth ed. United State of America: John Wiley \& Sons; 2007. 